\title{
FOREWORD
}

\section{Satellite Remote Sensing Beyond 2015}

\section{Compton J. Tucker}

NASA/Goddard Space Flight Center

Earth Science Division

Greenbelt, Maryland 20771 USA

Satellite remote sensing has progressed tremendously since the first Landsat was launched on June 23, 1972. Since the 1970s, satellite remote sensing and associated airborne and in situ measurements have resulted in vital and indispensable observations for understanding our planet through time. These observations have also led to dramatic improvements in numerical simulation models of the coupled atmosphere-land-ocean systems at increasing accuracies and predictive capability. The same observations document the Earth's climate and are driving the consensus that Homo sapiens is changing our climate through greenhouse gas emissions.

These accomplishments are the combined work of many scientists from many countries and a dedicated cadre of engineers who build the instruments and satellites that collect Earth observation data from satellites, all working toward the goal of improving our understanding of the Earth. This edition of the Remote Sensing Handbook (Vol. I, II, and III) is a compendium of information for many research areas of our Planet that have contributed to our substantial progress since the 1970s. Remote sensing community is now using multiple sources of satellite and in situ data to advance our studies, what ever they might be. In the following paragraphs, I will illustrate how valuable and pivotal role satellite remote sensing has played in climate system study over last five decades, The Chapters in the Remote Sensing Handbook (Vol. I, II, and III) provides many other specific studies on land, water, and other applications using EO data of last five decades,

The Landsat system of Earth-observing satellites has led the way in pioneering sustained observations of our planet. From 1972 to the present, at least one and sometimes two Landsat satellites have been in operation (Irons et al. 2012). Starting with the launch of the first NOAA-NASA Polar Orbiting Environmental Satellites NOAA-6 in 1978, improved imaging of land, clouds, and oceans and atmospheric soundings of temperature were accomplished. The NOAA system of polar-orbiting meteorological satellites has continued uninterrupted since that time, providing vital observations for numerical weather prediction. These same satellites are also responsible for the remarkable records of sea surface temperature and land vegetation index from the Advanced Very High Resolution Radiometers (AVHRR) that now span more than 33 years, although no one anticipated these valuable climate records from this instrument before the launch of NOAA-7 in 1981 (Cracknell 1997).

The success of data from the AVHRR led to the design of the MODIS instruments on NASA's Earth Observing System of satellite platforms that improved substantially upon the AVHRR. The first of the EOS platforms, Terra, was launched in 2000 and the second of these platforms, Aqua, was launched in 2002. Both of these platforms are nearing Roman 2 their operational life and many of the climate data records from MODIS will be continued with the VIIRS instrument on the polar orbiting meteorological satellites of NOAA. The first of these missions, the NPOES Preparation Project (NPP) was launched in 2012 with the first VIIRS instrument that is operating currently among several other instruments on this satellite. Continuity of observations is crucial for advancing our understanding of the Earth's climate system. Many scientists feel the crucial climate observations provided by remote sensing satellites are among the most important satellite measurements because they contribute to documenting the current state of our climate and how it is evolving. These key satellite observations of our climate are second in importance only to the polar orbiting and geostationary satellites needed for numerical weather prediction.

The current state-of-the-art for remote sensing is to combine different satellite observations in a complementary fashion for what is being studied. Let us review climate change as an excellent example of using disparate observations from multiple satellite and in situ sources to observe climate change, verify that it is occurring, and understand the various component processes. 


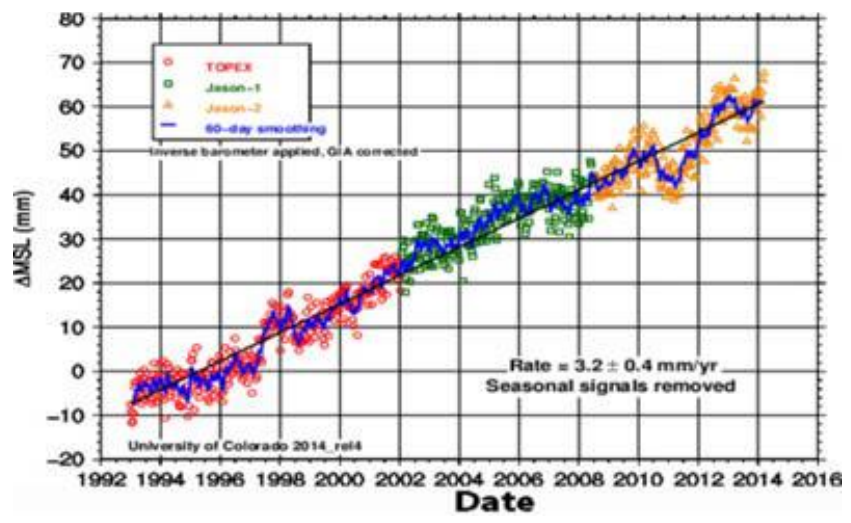

Remotely sensed climate observations provide the data to understand our planet and what forces our climate. The primary climate observation come from radar altimetry that started in late 1992 with Topex-Poseidon and has been continued by Jason-1 and Jason-2 to provide an uninterrupted record of global sea level. Changes in global sea level provide unequivocal evidence if our planet is warming, cooling, or staying at the same temperature. Radar altimetry from 1992 to date has shown global sea level increases of $\sim 3 \mathrm{~mm} / \mathrm{yr}$ and hence our planet is warming (Figure 1). Sea level rise has two components, thermal expansion and ice melting in the ice sheets of Greenland and Antarctica, and to a much lesser extent, in glaciers.

Figure 1. Sea level determined from three radar altimeters from later 1992 to the present. Sea level is the unequivocal indicator of the Earth's climate-when sea level rises, the planet is warming; when sea level falls, the planet is cooling (Gregory et al. 2013). Next we consider two very different satellite observations and one in situ observing system that enable us to understand the causes of sea level variations: total solar irradiance; variations in the Earth's gravity field; and the Argo floats that record ocean temperature and salinity with depth, respectively.

Figure 1. Sea level determined from three radar altimeters from later 1992 to the present. Sea level is the unequivocal indicator of the Earth's climate-when sea level rises, the planet is warming; when sea level falls, the planet is cooling (Gregory et al. 2013). Next we consider two very different satellite observations and one in situ observing system that enable us to understand the causes of sea level variations: total solar irradiance; variations in the Earth's gravity field; and the Argo floats that record ocean temperature and salinity with depth, respectively.

Observations of total solar irradiance have been made from satellites since 1979 and show total solar irradiance has varied only \pm 1 part in 500 over the past 35 years, establishing that our Sun is not to blame for global warming (figure 2). Thus we must look to other remotely-sensed climate observations to explain and confirm

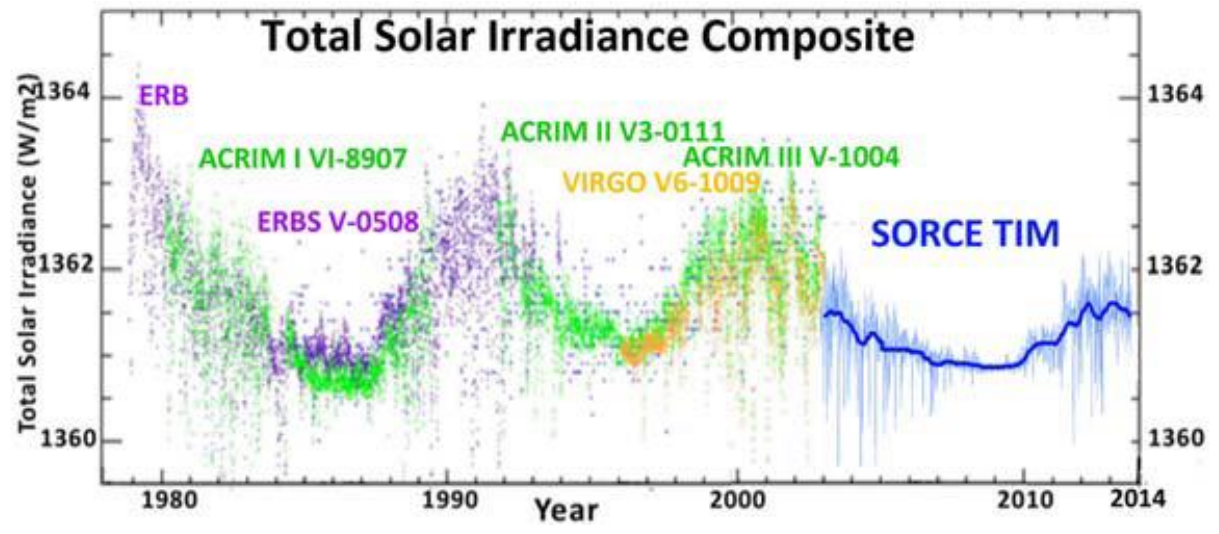

Figure 2. Total solar irradiance reconstructed from multiple instruments back to 1979 . The luminosity of our own sun varies only $0.1 \%$ over the course of the 11 -year solar cycle (Froehlich 2013). 
sea level rise. Since 2002, we have measured gravity anomalies from the Gravity Recovery and Climate Experiment Satellite or GRACE dual satellite system. GRACE data quantify ice mass changes from the Antarctic and Greenland ice sheets and concentrations of glaciers, such as in the Gulf of Alaska (Luthcke et al. 2013).

GRACE data are truly remarkable - their retrieval of variations in the Earth's gravity field is quantitatively and directly linked to mass variations. With GRACE data we are able for the first time to determine the mass balance with time of the Antarctic and Greenland ice sheets and concentrations of glaciers on land. GRACE data show sea level rise is $60 \%$ explained by ice loss from land (figure 3). GRACE data have many other uses such as the changes on ground water fluctuations and readers are directed to the GRACE project's web site if interested < http://www.csr.utexas.edu/grace/>.

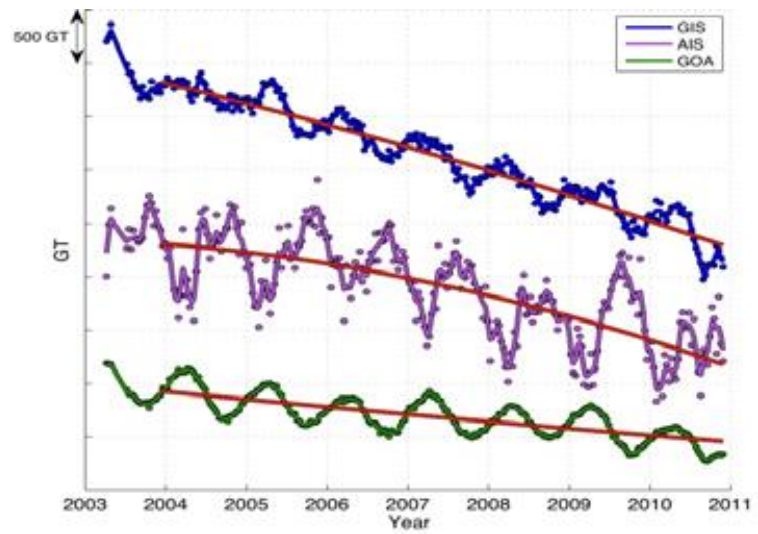

Figure 3. Ice mass variations from 2003 to 2010 for the Antarctica ice sheet (AIS), the Greenland ice sheet (GIS), and the Gulf of Alaska glaciers (GOA) using GRACE gravity data (Luthcke et al. 2013).

The other contributor to sea level rise is thermal expansion in the planet's oceans. This necessitates using diving and drifting floats in the Argo network to record temperature with depth (Romerich et al. 2009 \& figure 4). Argo floats are deployed from ships, they then submerge and descend slowly to $1000 \mathrm{~m}$ depth, recording temperature, pressure, and salinity as they descend. At $1000 \mathrm{~m}$ depth, they drift for ten days continuing their measurements of temperature and salinity. After ten days, they slowly descend to 3000 $\mathrm{m}$ and then ascend to the surface, all the time recording their measurements. At the surface, each float transmits all the data collected on the most recent excursion to a geostationary satellite and then descend again to repeat this process.

Argo temperature data show that $40 \%$ of sea level rise results from warming and thermal expansion of our oceans. Combining radar altimeter data, GRACE data, and Argo data provide confirmation of sea level rise and show what is responsible for it and in what proportions. With total solar irradiance being near-constant, what is driving global warming can be determined. Analysis of surface in situ air temperature coupled with lower tropospheric air temperature and stratospheric temperature data from remote sensing infrared and microwave sounders show the surface and near-surface is warming while the stratosphere is cooling. This is an unequivocal confirmation that greenhouse gases are warming the planet 


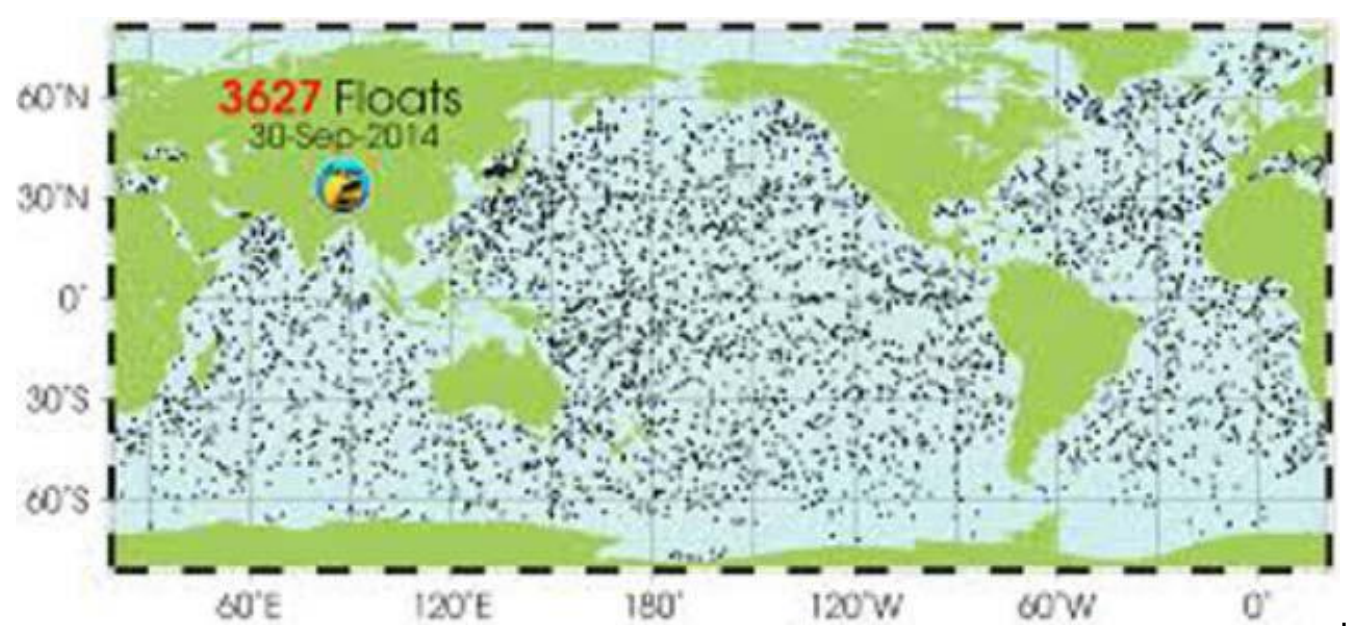

Figure 4. The latest picture of the 3,627 Argo floats that were in operation on September 30,2014 . These floats provide the data needed to document thermal expansion of the oceans < http://www.argo.ucsd.edu/>.

Many scientists are actively working to study the Earth's carbon cycle and there are several chapters in this Remote Sensing Handbook (Vol. I, II, and III) that deal with components of this undertaking. Much like simultaneous observations of sea level, total solar irradiance, the gravity field, ocean temperature, surface temperature, and atmospheric temperatures were required to determine if the Earth is warming and what is responsible, the carbon cycle will require several complimentary satellite and in situ observations (Cias et al. 2014)

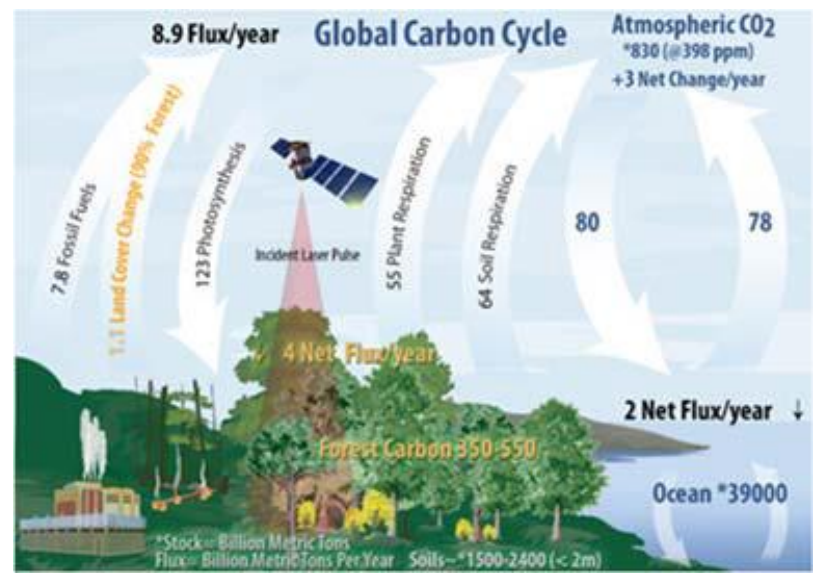

Figure 5. A representation of the global carbon cycle showing our best estimates of carbon fluxes and carbon reservoirs. A series of satellite observations are needed simultaneously to understand the carbon cycle and its role in the Earth's climate system (Cias et al. 2014).

Carbon cycles through reservoirs on the Earth's surface in plants \& soils, exists in the atmosphere as gases such as carbon dioxide $\left(\mathrm{CO}_{2}\right)$ \& methane $\left(\mathrm{CH}_{4}\right)$, and exists in ocean water in phytoplankton \& in marine sediments. $\mathrm{CO}_{2}$ and $\mathrm{CH}_{4}$ are released to the atmosphere from combustion of fossil fuels, by land cover changes on the Earth's surface, by respiration of green plants, and by decomposition of carbon in dead vegetation and in soils, including carbon in permafrost. The atmospheric concentrations of $\mathrm{CO}_{2}$ and $\mathrm{CH}_{4}$ control atmospheric and oceanic temperatures through their absorption of outgoing long wave radiation and thus also indirectly control sea level via regulation of planetary ice volumes.

Satellite-borne sensors provide simultaneous global carbon cycle observations needed for quantifying carbon cycle processes, i.e., to measure atmospheric $\mathrm{CO}_{2}$ concentrations and emission sources; to measure land and ocean photosynthesis; to measure the reservoir of carbon in plants on land and its change; to measure the extent of biomass burning of vegetation on land; and to measure soil respiration and decomposition, including 
decomposing carbon in permafrost. In addition to the required satellite observations, in situ observations are needed to confirm satellite-measured $\mathrm{CO}_{2}$ concentrations and determine soil ans vegetation carbon quantities. Understanding the carbon cycle requires a "full court press" of satellite and in situ observations because all of these observations must be made at the same time. Many of these measurements are have been made over the past thirty to forty years but new measurements are needed to quantify carbon storage in vegetation, atmospheric measurements are needed to quantify $\mathrm{CH}_{4} \mathrm{OC} 4$ and $\mathrm{CO} 2$ sources and sinks, better measurements are needed to quantify land respiration, and more explicit numerical carbon models need to be developed.

Similar work needs to be performed for the role of clouds and aerosols in climate because these are fundamental to understanding our radiation budget. We also need to improve our understanding of the global hydrological cycle.

While the rRemote sensing community has made tremendous progress since the 1970sover last five decades as captured in various Chapters of Remote Sensing Handbook (Vol. I, II, and III)., Chapters in Volume II and Volume III provide comprehensive understanding of land and water studies through detailed methods, approaches, algorithms, synthesis, and key references. Every type of remote sensing data obtained from systems such as optical, radar, LiDAR, hyperspectral, and hyperspatial are presented and discussed in different Chapters. Volume I sets the stage with Chapters in this Volume addressing remote sensing data characteristics, calibration, classification methods, and accuracies taking wide array of remote sensing data from wide array of platforms over last 5 decades. Volume I also brings in technologies closely linked with remote sensing such as GPS, GNSS, crowdsourcing, cloud computing, and remote sensing law. The chapters in Remote Sensing Handbook (Vol. I, II, and III) are written by leading and well accomplished remote sensing scientists of the world and competently edited by Prasad S. Thenkabail, Research Geographer-15, at U.S. Geological Survey. Wwe can look forward in the next ten to twenty years to improving our quantitative understanding of the global carbon cycle, understanding the interaction of clouds and aerosols in our radiation budget, and understanding the global hydrological cycle. There is much work to do: existing key climate observations must be continued, new satellite observations will be needed (e.g., recently launched NASA's Orbiting Carbon Observatory or OCO-2 atmospheric $\mathrm{CO}_{2}$ ), and we have well-trained scientists to undertake this work and continue the legacy of the past five decades.

References

Ciais, P. et al. 2014. Current systematic carbon-cycle observations and the need for implementing a policy-relevant carbon observing system. Biogeosciences 11(13): 35473602.

Cracknell, A. P. 1997. The Advanced Very High Resolution Radiometer (AVHRR).

London, Taylor \& Francis, London and Bristol UK, ISBN 074840209 8, 534 p.

Froehlich, C. 2013. Total Solar Irradiance: What Have We Learned from the Last Three Cycles and the Recent Minimum? Space Science Reviews 176(1-4): 237-252.

Gregory, J. M. et al. 2013. Twentieth-Century Global-Mean Sea Level Rise: Is the Whole Greater than the Sum of the Parts? Journal of Climate 26(13):4476-4499.

J. R. Irons, J. L. Dwyer, and J. A. Barsi 2012. The next Landsat satellite: The Landsat Data Continuity Mission. Remote Sensing of Environment 122:11-21, doi:10.1016/j.rse.2011.08.026.

Luthcke, S. B., Sabaka, T. J., Loomis, B. D. Arendt, A. A., McCarthy, J. J., and Camp, J. 2013. Antarctica, Greenland, and Gulf of Alaska land-ice evolution from an iterated GRACE global mascon solution. Journal of Glaciology 59(216): 613-631.

Roemmich, D. and the Argo Steering Team, 2009. Argo--The challenge of continuing 10 years of progress. Oceanography 22(3):46-55. 